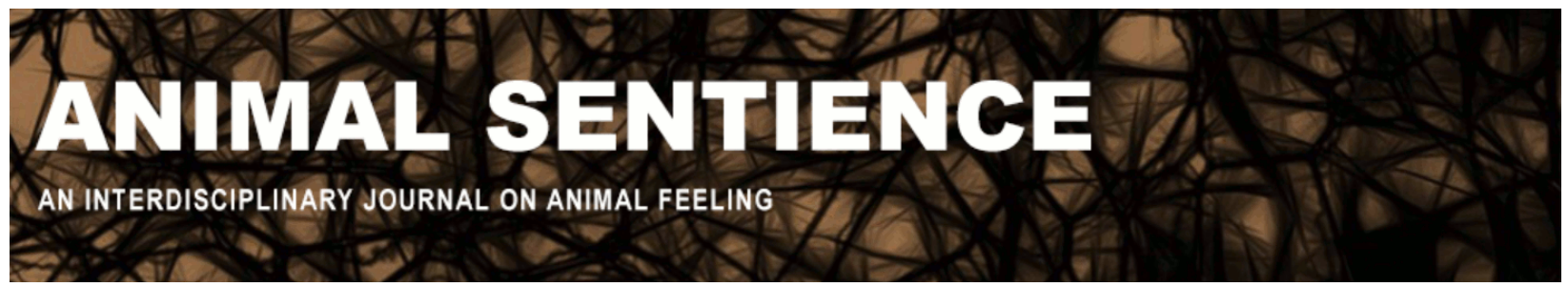

Morris, Paul (2017) Direct perception of animal mind. Animal Sentience 14(5) DOI: $10.51291 / 2377-7478.1236$

Date of submission: $2017-10-28$

Date of acceptance: 2017-11-04

(c) (i)




\title{
Direct perception of animal mind
}

Commentary on Kujala on Canine Emotions

\author{
Paul Morris \\ Department of Psychology \\ University of Portsmouth
}

\begin{abstract}
Kujala's (2017) target article is ostensibly focused on how everyday folk (fail to) make sense of canine emotions. However, the theories outlined in the article apply to making sense of all aspects of the mentality of both human and non-human animals. The target article neglects the fundamental arguments surrounding the problem of other minds. I explore the relevant arguments and briefly review approaches suggesting that our everyday-life sense that both human and non-human animals are thinking, feeling, emotional beings has a secure epistemological basis.
\end{abstract}

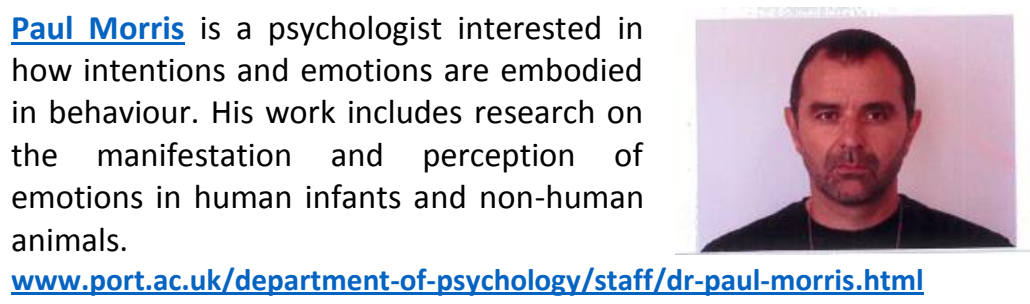

1. Can we ever know other minds? There is a very old joke about a stranger asking an aged farmer for directions to the nearest town, and the farmer replies "Well I wouldn't be starting from here." This is my response to the target article. Kujala's (2017) opening sentence makes the following claim "It is not possible to demonstrate that dogs (Canis familiaris) feel emotions, but the same is true for all other species, including our own." There is no doubt or equivocation - the author clearly believes this is a fact. Such a claim is in reality highly contentious.

2. The standard model of the problem of other minds. I begin here with another old joke: There are two types of psychologist: those who know they are dualists and those who don't. Although most psychologists are somewhat aware of the metaphysical problems associated with mind/body dualism, contemporary psychology seems remarkably comfortable with mind/behavior dualism. Indeed, the vast majority of definitions of contemporary psychology include the terms behavior and mind. Mind is thought to be accessed via inference from behavior both by everyday folk and research psychologists. The only difference is that the psychologist investigates the relationship systematically. The fundamental problem about knowing other minds arises because behavior is observable but mind is not. This is why Kujala claims that feelings cannot be demonstrated: because feelings are an aspect of mind and so they are essentially hidden.

3. The problems of dualism. The idea that mind and body/behavior are distinct entities has come under sustained attack for centuries. The most basic criticism of such dualism is that if 
mind and body/behavior have no properties in common, how can they interact? Many philosophers would regard this problem as a fatal flaw. Scientists and philosophers have proposed a number of solutions, e.g., non-reductive physicalism and reductive physicalism. Each approach has its own set of issues and problems. In the target article, there is no coverage of such foundational questions. My point here is not really to argue for any one position (although I will later get off the fence); my point is that the assumptions made in the target article are contentious, and the relevant debates are crucial to the question of how we know about canine emotions or any other psychological quality.

4. Solutions to the problems of other minds from a dualist perspective. If mind is invisible, why would we even think that another organism has a mind? One answer to this question has been the argument from analogy. I have observed that my mind controls my body, and I make the guess that a similar relationship between mind and behavior is the best explanation of the bodily movements I observe in other people (see Wittgenstein, 1953, for a critique of such an approach). This explanation has been refined in contemporary psychology. The claim is now that the leap from behavior to mind is the result of an evolutionary adaptation, "Attributing minds to others is innate" (Kujala, 2017, p. 3). This evolutionary adaptation is alleged to be a fundamental part of human social cognition. This explanation is one particular version of a family of explanations for human understanding of other minds that are covered by the umbrella term "theory of mind." Such approaches remain extremely popular despite telling criticism (Leudar \& Costall, 2009); the common link between all theory-of-mind approaches is the assumption that there must be some cognitive process or mechanism that is operating to allow people to bridge the gap between observable behavior and mind.

5. Theory of mind and the problem of anthropomorphism. Kujala cites a paper by Urquiza-Haas and Kotrschal (2015) in which the following definition of anthropomorphism is provided: "Humans readily attribute intentionality and mental states to living and non-living entities, a phenomenon known as anthropomorphism" (p. 167). Kujala explains that the cause of the fact that everyday folk readily make psychological attributions to animals - and apparently even to "vegetables or rocks" - is the innate cognitive mechanism she has identified. The crux of Kujala's argument is that our perception of canine emotions is the result of this innate mechanism of human social cognition. So, to use psychological terms to describe any aspect of the behaviour of a non-human animal is a category error, because a quality that is alleged to be uniquely human (i.e., psychological agency) is being ascribed to the non-human. It is difficult to think of a theoretical standpoint that is in greater disagreement with a Darwinian approach to psychology. Darwin (1871) could not have been any more explicit: "My object in this chapter is solely to show that there is no fundamental difference between man and the higher mammals in their mental faculties" (p. 35). We can of course be wrong about the particular feelings, emotions and intentions of both human and non-human animals, but it is not a category error to impute intentions, feelings and emotions to non-human animals (Fisher, 1991).

One very surprising claim about the relevant social cognition mechanism is that it leads people to perceive even vegetables and rocks as being psychological agents. I have read the original papers that are cited as evidence in support of this claim, and in reality, they provide little support for such a position. Kieseler and Kiesler (2005), for example, make no claim that 
participants perceive rocks as psychological agents; the claim is merely that rocks decorated by participants reflect aspects of the decorator's personality.

I have never met anybody who believes a vegetable or rock has feelings or intentions (positive or malign). There is a very funny scene in a famous comedy series (Fawlty Towers, Booth \& Cleese, 1975), where the protagonist (Basil Fawlty) starts beating his car with a tree branch after the car has broken down yet again. Basil shouts "Start you vicious bastard.... I'm warning you ... if you don't start l'll count to three ... don't say I haven't warned you ... I'm going to give you (i.e. the car) a damn good thrashing." This is funny precisely because it is so ridiculous to think that the car has broken down intentionally.

I sometimes shout at inanimate objects, but I don't really believe they are out to get me. However, when I see my dog standing by the back door, pawing at the handle, occasionally pushing at the door, I do indeed believe that my dog wants to go out. The claim that everyday folk perceive vegetables and rocks as psychological agents is used in the target article to show how deeply sceptical we must be about the claims of everyday folk about their dogs. There is an alternative view. The vast majority of people (perhaps with the exceptions of devotees of animist religions, young children and people enduring a florid psychotic episode) do not perceive vegetables or rocks as psychological beings; but people are in agreement with Darwin, that both human and non-human animals are indeed psychological agents.

6. Embodiment and the rejection of both materialism and mind/behaviour dualism. Theory-ofmind approaches are explicitly dualist and indeed there are psychologists who would vigorously defend a neo-Cartesian position (e.g., Fodor, 1980). There are also neuroscientists who are thoroughgoing materialists, regarding mind as some kind of epiphenomenon. However, alternative approaches to mind that are neither dualist nor materialist have also been developing over the past century. Such approaches can loosely be placed under the umbrella term of "embodiment." The essence of such approaches is that mind is embodied in behavior. The historical roots of this approach are diverse. For example, the linguistic behaviorists (e.g., Ryle, 1949) are explicit that psychological qualities such as intelligence do exist, but only as they are manifest in behavior. Other influences include Husserl's phenomenology of embodiment, the pragmatism of John Dewey, and George Herbert Mead's psychology of the act.

The key point is that mind is directly available in behavior and therefore our knowledge of mind has a secure epistemological basis. One example of the application of such ideas in contemporary psychology is the work by Reddy (2010) on social engagement in human infancy. Bavidge and Ground (1998) provide a very scholarly but accessible account of how such ideas are relevant to our understanding of animal minds (see also Murray, 2008).

In summary, I do not agree with Kujala's fundamental assumptions about the nature of the problem of how we know about canine emotions. But regardless of whether a reader is sympathetic to my particular theoretical orientation, I think it is impossible to properly address how we know animal minds without a thorough exploration of the relevant philosophical assumptions. 


\section{References}

Bavidge, M. \& Ground, I. (1998). Can we understand animal minds? Bristol: Bristol Classical Press.

Booth, C. \& Cleese, J. (writers), Spiers, B. \& Howard-Davies, J. (directors) (1975). Fawlty Towers. [Television series]. London: BBC.

Darwin, C. (1871). The descent of man, and selection in relation to sex. New York: D. Appleton.

Fisher, J. (1991). Disambiguating anthropomorphism: An interdisciplinary study. In P. P. G. Bateson \& P. H. Klopfer (Eds.), Perspectives in ethology (Vol. 9). New York: Plenum Publishing Cooperation.

Fodor, J.A. (1980). The language of thought. Harvard: Harvard University Press.

Kiesler, T. \& Kiesler, S. (2005). My pet rock and me: an experimental exploration of the self extension concept. In G. Menon \& A. R. Rao (Eds.), Advances in consumer research (pp. 365370). Duluth, MN: Association for Consumer Research.

Kujala, M.V. (2017). Canine emotions as seen through human social cognition. Animal Sentience 14(1).

Leudar, I. \& Costall, A. (2009). Against theory of mind. London: Palgrave Macmillan.

Murray, M.M. (2008). Nature red in tooth and claw: Theism and the problem of animal suffering. Oxford: Oxford University Press.

Reddy, V. (2010). How infants know minds. Harvard: Harvard University Press.

Ryle, G. (1949). The concept of mind. London: Hutchinson.

Urquiza-Haas, E. G. \& Kotrschal, K. (2015). The mind behind anthropomorphic thinking: attribution of mental states to other species. Animal Behaviour, 109, 167-176.

Wittgenstein, L. (1953). The philosophical investigations. Tr. by G.E.M. Anscombe. N.J.: Prentice Hall. 


\section{ANIMAL CONSCIOUSNESS}

On November 17-18, 2017, the NYU Center for Mind, Brain and Consciousness, the NYU Center for Bioethics, and NYU Animal Studies will host a conference on Animal Consciousness.

This conference will bring together philosophers and scientists to discuss questions such as: Are invertebrates conscious? Do fish feel pain? Are nonhuman mammals self-conscious? How did consciousness evolve? How does research on animal consciousness affect the ethical treatment of animals? What is the impact of issues about animal consciousness on theories of consciousness and vice versa? What are the best methods for assessing consciousness in nonhuman animals?

\section{Speakers and panelists include:}

Colin Allen (University of Pittsburgh, Department of History \& Philosophy of Science), Andrew Barron (Macquarie, Cognitive Neuroethology), Victoria Braithwaite (Penn State, Biology), Peter Carruthers (Maryland, Philosophy), Marian Dawkins (Oxford, Zoology), Dan Dennett (Tufts, Philosophy), David Edelman (San Diego, Neuroscience),

Todd Feinberg (Mt. Sinai, Neurology), Peter Godfey-Smith (Sydney, Philosophy), Lori Gruen (Wesleyan, Philosophy), Brian Hare (Duke, Evolutionary Anthropology), Stevan Harnad (Montreal, Cognitive Science), Eva Jablonka (Tel Aviv, Cohn Institute), Björn Merker (Neuroscience), Diana Reiss (Hunter,

Psychology), Peter Singer (Princeton, Philosophy), Michael Tye (Texas, Philosophy)

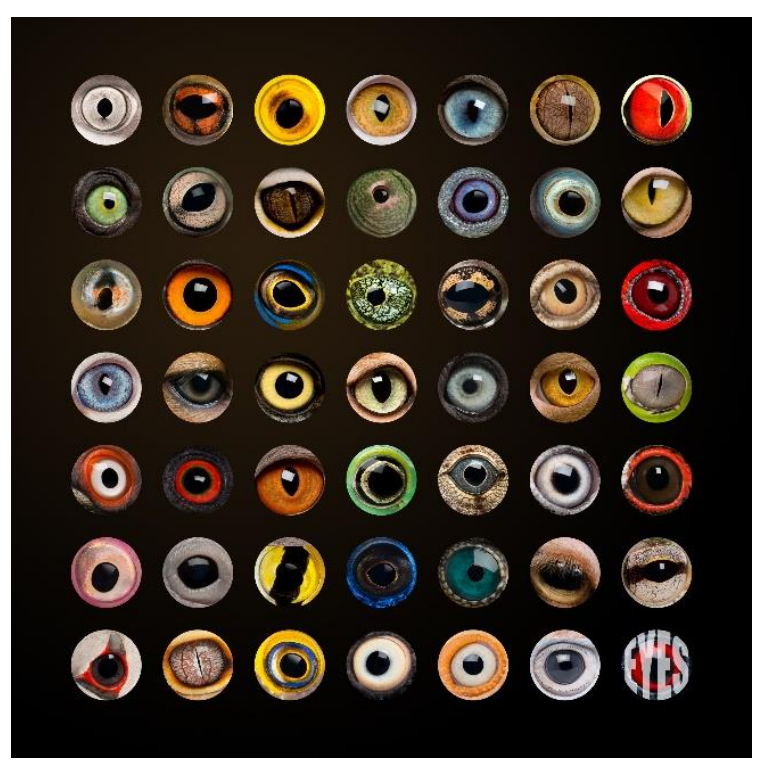

Organizers: Ned Block, David Chalmers, Dale Jamieson, S. Matthew Liao.

The conference will run from 9am on Friday November 17 to $6 \mathrm{pm}$ on Saturday November 18 at the NYU Cantor Film Center (36 E 8th St).

Friday sessions will include "Invertebrates and the evolution of consciousness", "Do fish feel pain?", and "Animal consciousness and ethics".

Saturday sessions will include "Animal self-consciousness", "Animal consciousness and theories of consciousness", and a panel discussion.

A detailed schedule will be circulated closer to the conference date.

Registration is free but required.

\section{Register here.}

\section{See also the conference website}

